\section{Acknowledgments}

This work was supported by grants from the NIH to OAM (R24 DK092759; R01 DK62876), and from the American Diabetes Association to ZL (1-18-PDF-087).

\section{References}

1. Cawthorn WP, Scheller EL, Learman BS, et al. Bone marrow adipose tissue is an endocrine organ that contributes to increased circulating adiponectin during caloric restriction. Cell Metab. 2014;20(2):368375 .

2. Li Z, Hardij J, Bagchi DP, Scheller EL, MacDougald OA. Development, regulation, metabolism and function of bone marrow adipose tissues. Bone. 2018;110:134-140.

3. Zhou BO, Yu H, Yue R, et al. Bone marrow adipocytes promote the regeneration of stem cells and haematopoiesis by secreting SCF. Nat Cell Biol. 2017;19(8):891-903.

4. Li Z, Hardij J, Evers SS, et al. G-CSF partially mediates effects of sleeve gastrectomy on the bone marrow niche. J Clin Invest. 2019;130:2404-2416

5. Zhang Z, Huang Z, Ong B, Sahu C, Zeng H, Ruan HB. Bone marrow adipose tissue-derived stem cell factor mediates metabolic regulation of hematopoiesis. Haematologica. 2019;104(9):1731-1743.

6. Czechowicz A, Kraft D, Weissman IL, Bhattacharya D. Efficient transplantation via antibody-based clearance of hematopoietic stem cell niches. Science. 2007;318(5854):1296-1299

7. Nocka K, Majumder S, Chabot B, et al. Expression of c-kit gene products in known cellular targets of $\mathrm{W}$ mutations in normal and $\mathrm{W}$ mutant mice--evidence for an impaired c-kit kinase in mutant mice. Genes Dev. 1989;3(6):816-826.

8. Bosbach B, Deshpande S, Rossi F, et al. Imatinib resistance and microcytic erythrocytosis in a KitV558Delta;T669I/+ gatekeepermutant mouse model of gastrointestinal stromal tumor. Proc Natl Acad Sci U S A. 2012;109(34):E2276-E2283.

9. Song L, Liu M, Ono N, Bringhurst FR, Kronenberg HM, Guo J. Loss of wnt/beta-catenin signaling causes cell fate shift of preosteoblasts from osteoblasts to adipocytes. J Bone Miner Res. 2012;27(11):23442358 .

10. Mizoguchi T, Pinho S, Ahmed J, et al. Osterix marks distinct waves of primitive and definitive stromal progenitors during bone marrow development. Dev Cell. 2014;29(3):340-349.

11. Calvi LM, Adams GB, Weibrecht KW, et al. Osteoblastic cells regulate the haematopoietic stem cell niche. Nature. 2003;425(6960):841846.

12. Visnjic D, Kalajzic Z, Rowe DW, Katavic V, Lorenzo J, Aguila HL. Hematopoiesis is severely altered in mice with an induced osteoblast deficiency. Blood. 2004;103(9):3258-3264.

13. Ding L, Saunders TL, Enikolopov G, Morrison SJ. Endothelial and perivascular cells maintain haematopoietic stem cells. Nature. 2012;481(7382):457-462

14. Scheller EL, Khandaker S, Learman BS, et al. Bone marrow adipocytes resist lipolysis and remodeling in response to beta-adrenergic stimulation. Bone. 2019;118:32-41.

\title{
New potential players in hepcidin regulation
}

\author{
Maxwell Chappell and Stefano Rivella
}

Division of Hematology, Department of Pediatrics, Children's Hospital of Philadelphia, Cell and Molecular Biology Graduate Group, University of Pennsylvania, Abramson Research Center, Philadelphia, PA, USA

E-mail: STEFANORIVELLA - rivellas@email.chop.edu

doi:10.3324/haematol.2019.224311

T he manuscript by Liu and colleagues, published in this issue of Haematologica, reports the identification of novel compounds able to increase hepcidin expression in normal mice as well as in animals affected by hemochromatosis and $\beta$-thalassemia intermedia (or non-transfusion-dependent thalassemia) (Figure 1A). ${ }^{1}$

Hepcidin is the master regulator of iron secreted from the liver and acts on ferroportin, a transmembrane protein that functions as an iron exporter. ${ }^{2,3}$ Once hepcidin binds ferroportin, the complex is rapidly degraded, preventing iron egress. ${ }^{2,3}$ Ferroportin is expressed in many types of cells, including enterocytes and macrophages. ${ }^{2,3}$ Therefore, the relative abundance of hepcidin in the circulation and ferroportin on cell membranes control iron absorption (from enterocytes) and iron recycling (from macrophages). ${ }^{2,3}$

Hepcidin expression is regulated by iron, inflammation and erythropoiesis., ${ }^{2,3}$ With regard to iron-mediated control of hepcidin, this is achieved through at least two mechanisms. The first senses the amount of intracellular iron in liver sinusoidal endothelial cells and responds by synthesizing BMP6, and other similar ligands, belonging to the TGF $\beta$-like family. ${ }^{2 \cdot 4}$ Increased intracellular concentration of iron leads to secretion of BMP6 from these cells. ${ }^{2-4}$ As a consequence, BMP6 binds and activates receptors that trigger phosphorylation of a SMAD complex and stimulate hepcidin expression in hepatic cells. ${ }^{2-4}$

The second mechanism senses the iron in circulation by recognizing iron-loaded transferrin molecules. ${ }^{3}$
Molecules such as HFE, transferrin receptor-2, and others communicate intracellularly when the transferrin saturation levels increase. ${ }^{3}$ It has been hypothesized that this sensing complex potentiates the SMAD complex activated by BMP6. Alternatively, or in addition, it has been suggested that this complex acts upon hepcidin expression by decreasing the ERK1/2 pathway. ${ }^{10}$

Under conditions that require enhanced red cell production (as a consequence of a transient or chronic anemia), hepcidin synthesis is normally suppressed. ${ }^{2}$ A few factors have been identified that could play a role in this mechanism, such as erythroferrone and platelet-derived growth factor $\mathrm{BB} .^{7,8}$ In particular, erythroferrone is secreted by erythroid cells and acts as a trap ligand, limiting the activity of BMP6 and other similar molecules.

Another player in the regulation of hepcidin is the molecule matriptase-2 (or TMPRSS6)., ${ }^{2,3}$ This molecule prevents hepcidin overexpression, which could lead to hypoferremia and anemia. ${ }^{3,10}$ Although it is unclear which pathways and molecules control TMPRSS6, it has been shown that TMPRSS6 is required for erythropoietinmediated hepcidin suppression in mice. ${ }^{11,12}$

In primary forms of hemochromatosis, patients show excessive iron absorption and suffer from iron overload (Figure 1A) ${ }^{7,8}$ This happens when hepcidin, or other genes that control its expression, are mutated. ${ }^{2,3}$ In secondary forms of hemochromatosis (as in $\beta$-thalassemia), the anemia triggers increased iron absorption, likely by increased expression of erythroferrone and other hypox- 
A

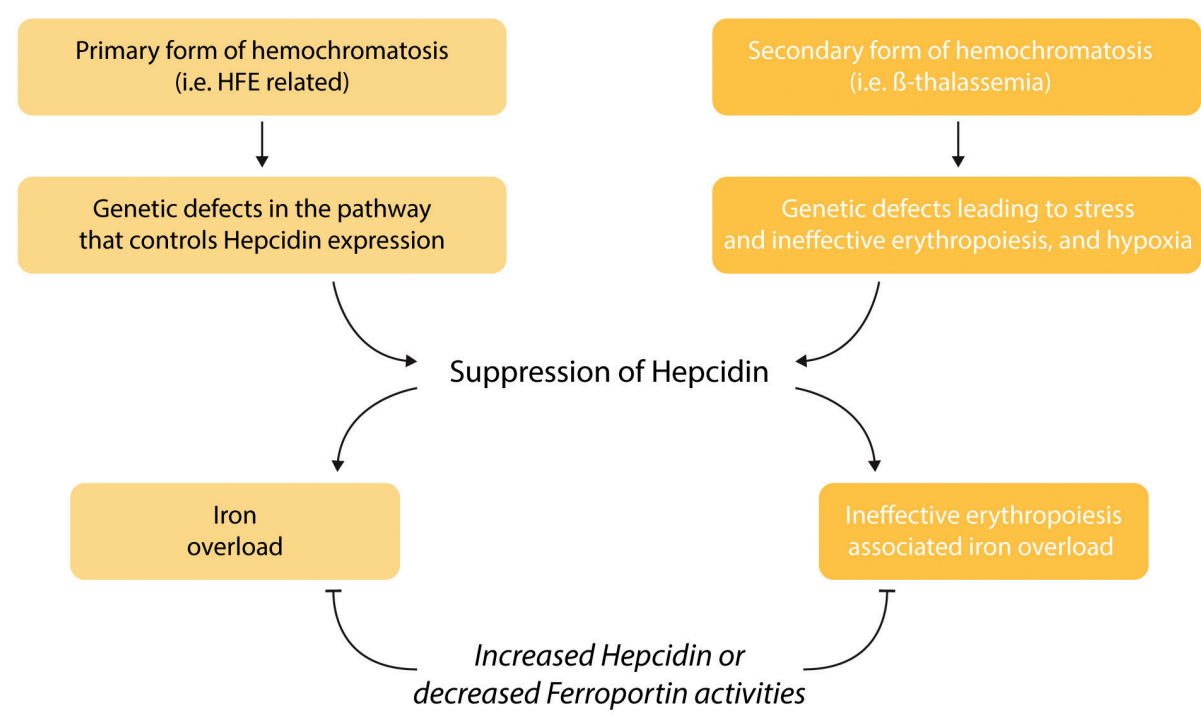

B

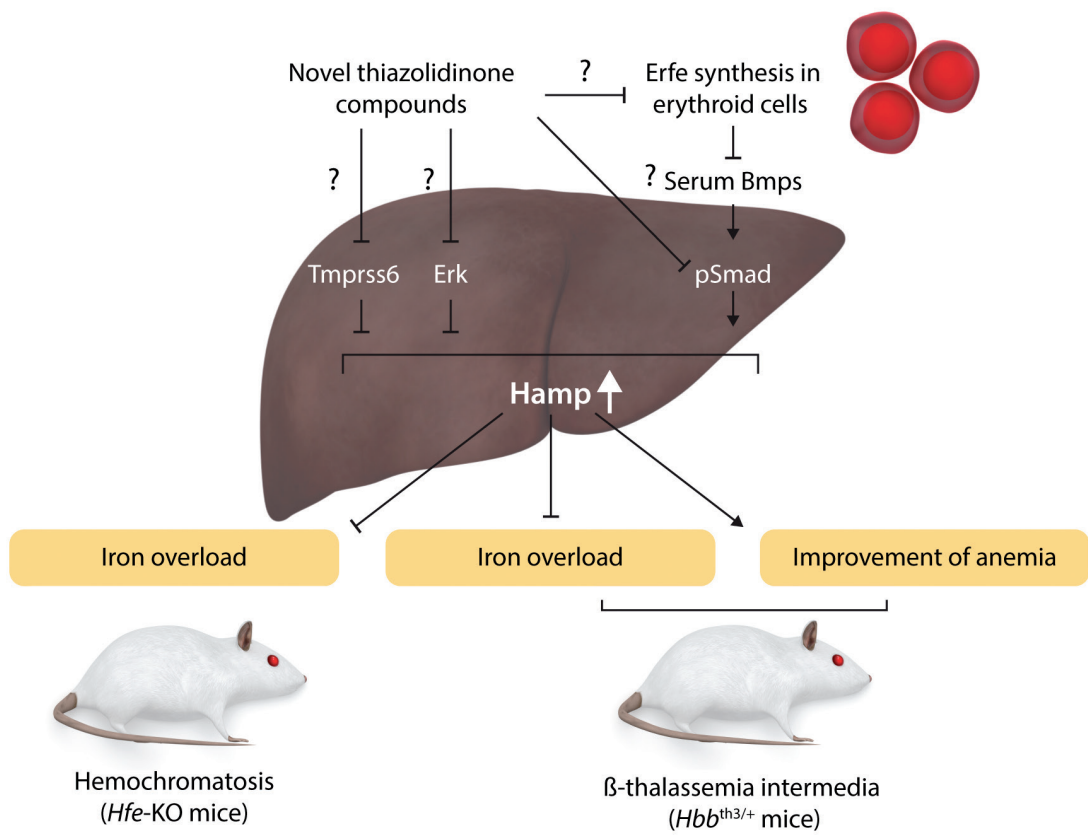

Figure 1. Role of hepcidin and novel thiazolidinone compounds in the treatment of hemochromatosis and $\beta$-thalassemia. (A) Relationship between disease, genetic mutations, hepcidin levels, drug administration and phenotype in primary and secondary forms of hemochromatosis. (B) Potential mechanisms of action and therapeutic effects of new thiazolidinone compounds in hemochromatosis and $\beta$-thalassemia.

ia-related molecules that converge on suppressing hepcidin synthesis or increasing ferroportin expression (Figure 1A)., 2,3,13

Conversely, mutations in the TMPRSS6 gene lead to overexpression of hepcidin. In this case, patients suffer from a condition indicated as iron-refractory iron deficiency anemia or IRIDA. ${ }^{14}$ These individuals suffer from a form of anemia that typically does not improve with oral iron treatment, but requires parenteral iron administration. ${ }^{14}$

The elucidation of these pathways and their association with disease led to the development of pharmacological compounds that increase hepcidin expression, mimic its activity, or decrease ferroportin activity, which can decrease iron absorption and improve iron overload in primary and secondary forms of hemochromatosis (Figure 1A). ${ }^{15,16}$ Intriguingly, the same drugs also showed beneficial effects on anemia in animal models of nontransfusion-dependent thalassemia (Figure 1A). ${ }^{13,17,18}$ In this case, it was observed that these drugs not only decreased iron absorption, but also erythroid iron intake..$^{13,17,18}$ In thalassemic erythroid progenitor cells, this can reduce the detrimental effects of oxidative stress triggered by the excess of iron and heme not included in normal hemoglobin molecules. ${ }^{13,17,18}$ This improves the quality and lifespan of red blood cells, and increases hemoglobin levels. ${ }^{13,17,18}$ The overall effect is to improve ineffective erythropoiesis and the associated iron overload (Figure 1A).

So far, most of the compounds identified as leading to 
increased hepcidin expression show a very specific activity (i.e. hepcidin mimetics or ferroportin inhibitors). ${ }^{15,19}$ In general, these drugs belong to one of four main categories: (i) hepcidin mimetics; (ii) hepcidin inducers; (iii) ferroportin inhibitors; and (iv) erythroferrone inhibitors. TMPRSS6 inhibitors can be defined as hepcidin inducers and/or BMP/SMAD pathway activators.

The ideal drug should be administered orally or injected subcutaneously very infrequently, having a long lifespan and prolonged activity. The drug should also show a large spectrum of activity, so that it can limit iron absorption in disorders such as non-transfusion-dependent thalassemia and HFE-related hemochromatosis, but also in conditions in which iron absorption is further increased (e.g., $\beta$-thalassemia major), or in which iron absorption needs to be further suppressed to achieve a significant benefit (as in polycythemia vera). ${ }^{15,18,19}$ The drug should also have no side effects, particularly under conditions of chronic administration. Obviously, low cost of production would also be desirable. Furthermore, and equally important, the drug should have a clear mechanism of action.

The compounds described by Liu and colleagues are derivatives of thiazolidinones, a group of versatile drugs which are also being developed for numerous clinical applications, such as anti-tuberculosis, antimicrobial, anti-cancer, anti-inflammatory, and antiviral agents. ${ }^{20}$ These new compounds increase expression of hepcidin and improve several parameters (related to both iron overload and anemia) in mice affected by primary and secondary forms of hemochromatosis (Figure 1B).

In particular, in mice affected by hemochromatosis, the compounds described by Liu and colleagues ameliorated abnormal iron parameters, improved iron overload, and induced iron redistribution from the liver to the spleen. In mice affected by non-transfusion-dependent thalassemia, these compounds also ameliorated iron overload. In addition, as ineffective erythropoiesis was also improved, red blood cell production and hemoglobin levels increased (Figure 1B).

As described in their article, these novel thiazolidinone derivatives appear to act on hepcidin expression through a variety of mechanisms, such as promoting Smad1/5/8 signaling, repressing Erk1/2 phosphorylation and decreasing Tmprss6 activity (Figure 1B). Additionally, these compounds seemed to target potential erythroid regulators (such as erythroferrone), thereby further contributing to hepcidin upregulation (Figure 1B). However, the target and mechanism of action of these compounds have not been completely elucidated.

Given their many effects, there is some concern that these drugs may be relatively unselective and affect additional targets and pathways. This would be even more relevant if these drugs were to become used in a chronic fashion. Future studies should, therefore, focus on determining how these drugs interact with their target and exclude unwanted effects.

In summary, these novel compounds are very promis- ing and expand the armamentarium of drugs that could benefit patients affected by disorders in which increased hepcidin expression is desirable. If proven to be safe, selective, and effective, their use will increase the chance that one or more compounds will reach the clinic, while competition between different drugs will likely diminish costs.

\section{References}

1. Liu J, Liu W, Liu Y, et al. New thiazolidinones reduce iron overload in mouse models of hereditary hemochromatosis and $\beta$-thalassemia. Haematologica. 2019;104(9):1768-1781.

2. Rivella S. Iron metabolism under conditions of ineffective erythropoiesis in beta-thalassemia. Blood. 2019;133(1):51-58.

3. Muckenthaler MU, Rivella S, Hentze MW, Galy B. A red carpet for ion metabolism. Cell. 2017;168(3):344-361.

4. Rausa M, Pagani A, Nai A, et al. Bmp6 expression in murine liver non parenchymal cells: a mechanism to control their high iron exporter activity and protect hepatocytes from iron overload? PLoS One. 2015;10(4):e0122696.

5. D'Alessio F, Hentze MW, Muckenthaler MU. The hemochromatosis proteins HFE, TfR2, and HJV form a membrane-associated protein complex for hepcidin regulation. J Hepatol. 2012;57(5):1052-1060.

6. Chen $\mathrm{H}$, Choesang $\mathrm{T}$, Li H, et al. Increased hepcidin in transferrintreated thalassemic mice correlates with increased liver BMP2 expression and decreased hepatocyte ERK activation. Haematologica. 2016;101(3):297-308.

7. Kautz L, Jung G, Valore EV, Rivella S, Nemeth E, Ganz T. Identification of erythroferrone as an erythroid regulator of iron metabolism. Nat Genet. 2014;46(7):678-684

8. Sonnweber T, Nachbaur D, Schroll A, et al. Hypoxia induced downregulation of hepcidin is mediated by platelet derived growth factor BB. Gut. 2014;63(12):1951-1959.

9. Arezes J, Foy N, McHugh K, et al. Erythroferrone inhibits the induction of hepcidin by BMP6. Blood. 2018;132(14):1473-1477.

10. Wahedi M, Wortham AM, Kleven MD, et al. Matriptase-2 suppresses hepcidin expression by cleaving multiple components of the hepcidin induction pathway. J Biol Chem. 2017;292(44):18354-18371.

11. Nai A, Rubio A, Campanella A, et al. Limiting hepatic Bmp-Smad signaling by matriptase- 2 is required for erythropoietin-mediated hepcidin suppression in mice. Blood. 2016;127(19):2327-2336.

12. Frydlova J, Rychtarcikova Z, Gurieva I, Vokurka M, Truksa J, Krijt J. Effect of erythropoietin administration on proteins participating in iron homeostasis in Tmprss6-mutated mask mice. PLoS One. 2017;12(10):e0186844

13. Gardenghi S, Marongiu MF, Ramos P, et al. Ineffective erythropoiesis in beta-thalassemia is characterized by increased iron absorption mediated by down-regulation of hepcidin and up-regulation of ferroportin. Blood. 2007;109(11):5027-5035.

14. Finberg KE, Heeney MM, Campagna DR, et al. Mutations in TMPRSS6 cause iron-refractory iron deficiency anemia (IRIDA). Nat Genet. 2008;40(5):569-571.

15. Casu C, Nemeth E, Rivella S. Hepcidin agonists as therapeutic tools Blood. 2018;131(16):1790-1794.

16. Guerra A, Musallam KM, Taher AT, Rivella S. Emerging therapies. Hematol Oncol Clin North Am. 2018;32(2):343-352.

17. Casu C, Aghajan M, Oikonomidou PR, Guo S, Monia BP, Rivella S. Combination of Tmprss6- ASO and the iron chelator deferiprone improves erythropoiesis and reduces iron overload in a mouse model of beta-thalassemia intermedia. Haematologica. 2016;101(1):e8-e11.

18. Casu C, Oikonomidou PR, Chen $\mathrm{H}$, et al. Minihepcidin peptides as disease modifiers in mice affected by beta-thalassemia and polycythemia vera. Blood. 2016;128(2):265-276.

19. Oikonomidou PR, Casu C, Rivella S. New strategies to target iron metabolism for the treatment of beta thalassemia. Ann N Y Acad Sci. 2016;1368(1):162-168.

20. Kaur Manjal S, Kaur R, Bhatia R, et al. Synthetic and medicinal perspective of thiazolidinones: a review. Bioorg Chem. 2017;75:406-423. 